\title{
REPRESENTAÇÕES DE GÊNERO E MORALIDADE NA PRÁTICA PROFISSIONAL DA ENFERMAGEM ${ }^{1}$
}

\author{
GENDER REPERSENTATIONS AND MORALITY IN THE NURSING PROFESSION \\ REPRESENTACIONES DE GÉNERO Y MORALIDAD EN LA PRÁCTICA PROFESIONAL \\ DE LA ENFERMERÍA
}

\author{
Lourdes Bandeira² \\ Eleonora M. de Oliveira ${ }^{3}$
}

\begin{abstract}
RESUMO: Este texto é parte de um diálogo travado entre as autoras a partir de duas pesquisas: uma sobre "As ambigüidades profissionais e condições de trabalho e de cidadania das enfermeiras estudo de caso comparativo entre o Distrito Federal e São Paulo" e a outra sobre "O impacto das condições de trabalho das enfermeiras do Hospital São Paulo em vida sexual e reprodutiva".

No seio das profissões de saúde, a enfermagem ocupa lugar singular. Distingue-se tanto pela sua importância numérica, quanto pela prática profissional quase exclusivamente feminina. Culturalmente, cuidar é atribuída como tarefa de mulher( enfermeira, mãe, professora, assistente social ): tratar é tarefa de homem ( médico, pai, provedor). A dicotomização entre cuidar e tratar define uma série de outros conflitos, de relações de poder e de hierarquia que se estabelecem na prática profissional da enfermagem. Tais conflitos podem ser associados: a) ao mito fundador de origem da enfermagem, gerador de uma moralidade e de uma competência que condicionam a prática profissional; b)a feminilidade, a maternagem, a gestão da intimidade e aos cuidados dos corpos, ou seja, as representações sociais da enfermagem em relação 'a condição de gênero; c) ao caráter androcêntrico das relações de poder e de sexualidade que subjazem no espaço profissional da enfermagem.
\end{abstract}

PALAVRAS CHAVE: Gênero, Identidade, Enfermagem, Poder

ABSTRACT: This text is part of a dialogue betwween the authorserlating to two reaearch projects: one on "The professional ambiguities, work cinditions and the citizenship of nurses - a comparative study in the Federal District and São Paulo"and the other on "The impact of work conditions on the nurses in the Hospital São Paulo as to sexual and reproductive life".

Nursing occupies a singular place in the health professions. Is is differentiated by numeric importance as well as by a professional practice which is almost exclusively feminine. Culturally, to care is attributed as a woman's task (nurse, mother teacher, social worker, etc.); to treat is a man's task (doctor, father, provider, etc.) The dichotomy between caring and treating deines other confkicts, erlations of power, and of hiearchies established in the professional practivee of nursing. These conflicts may be associated with: a) the founding myth of the origin of nursing, generator of a morality and a competence which condition htis professional practice; b) feminility, mothering, the administration of intimacy and body care, that is, the social representations of nursingwith respect to gender; c) the androcentric character of power relations and those of sexuality which subsume the professional space of nursing.

KEYWORDS: Gender, Identity, Nursing, Power

\footnotetext{
- Texto apresentado no VII Congresso Brasileiro de Sociologia realizado na Universidade de Brasília - UnB, no período de 1 a 5 de agosto de 1997.

2 Profa. Adjunta do Depto. de Sociologia - UnB

${ }^{3}$ Profa. Livre Docente do Depto. de Enfermagem e Centro de Saúde Coletiva da UNIFESP.
}

R. Bras. Enferm. Brasília, v. 51, n . 4, p. 677-696 out./dez. 1998 
RESUMEN: La enfermería ocupa un lugar singular entre las profesiones de salud,. Se distingue tanto por su importancia numérica, como por la práctica profesional, casi exclusivamente femenina. Desde el punto de vista cultural, cuidar es tarea de mujer (enfermera, madre, profesora, asistente social, etc. ): tratar es tarea de hombre (médico, padre, provedor). La dicotomia entre cuidar y tratar define otros conflictos de relación de poder y jerarquia que se establecen en la práctica profesional de la enfermería. Tales conflictos pueden ser asociados: a) al mito fundador de orígen de la enfermería. generador de una moral y de una rivalidad que condicionan la práctica profesional; b) la femineidad, la maternidad, la gestion de la intimidad y los cuidados de los cuerpos, o sea, las representaciones sociales de la enfermería en relación a la condición de género; c) al carácter androcéntrico de las relaciones de poder y de sex\&alidad que estan subyacen en el espacio profesional.

PALABRAS CLAVE: Género, Identidad, Enfermería, Poder

\section{INTRODUÇÃO ${ }^{4}$}

No seio das profissões de saúde, a profissão de enfermagem ocupa lugar singular. Distingue-se tanto pela sua importância numérica, quanto pela prática profissional quase exclusivamente feminina, assalariada e hospitalar pública e privada ${ }^{5}$, centralizada na atividade orientada ao cuidado da saúde de doentes hospitalizados. Assim, "... falar do trabalho de enfermeira é falar, portanto, do trabalho de mulheres" (Fonseca, 1996, p.63).

Ao gesto técnico, do ato do cuidar, se acrescenta um domínio de competência e de responsabilidade largamente determinado do exteriorpelas práticas e prescrições médicas, consideradas como um saber mais legítimo. A prática da enfermagem usufrui, sem dúvida de um monopólio garantido por uma regulação, entretanto, seu status como profissão paramédica acentua sua dependência em relação aos profissionais médicos. Cuidar é tarefa de mulher - enfermeira; tratar é tarefa de homem - médico. "A dicotomização entre tratar e cuidar define, desde então e desta forma, os conflitivos espaços territoriais dos personagens que cercam a doença e o doente; de um lado os médicos, aos quais se atribui a legitimidade da qualificação profissional e, de outro, o pessoal da enfermagem, dos quais se espera que venham a ser devotados ao seu destino de "auxiliar" do médico....". (Fonseca, 1996, p.64)

Neste sentido, evidenciam-se duas características: primeira, há nesta assertiva a negação de uma subjetividade feminina da condição de um sujeito autônomo e próprio, cuja existência é filtrada pela naturalização, destinando-a à subserviência; segundo, há uma moralidade interiorizada que produz-se como vocação e como ação moral. Este traço subjacente se çonsolida em uma perspectiva sócio-moral do sujeito e é o que o situa em relação áos processos interativos com os demais.

No diálogo travado entre a enfermagem e as ciências sociais evidenciam-se práticas sociais distintas que informam saberes e poderes também diferenciados. No âmbito das ciências da saúde, podemos distinguir a existência de práticas sociais entre o curar (medicina) e o cuidar (enfermagem). ${ }^{6}$ É nosso objeto de estudo a compreensão da prática social do cuidar da saúde, próprio da profissão de enfermagem, pensada a partir das relações de gênero e de classe, enquanto objetos sociológicos que espelham relações hierárquicas de poder entre os saberes 
institucionalizados e normatizados de curar e cuidar. O gesto técnico do ato de cuidar é acrescido de um domínio de competência e de responsabilidade largamente determinado por outros através das práticas e prescrições médicas, consideradas equivocadamente como um saber mais legítimo e mais nobre do que qualquer outra esfera do conhecimento integral sobre a pessoa humana. É neste quadro que a profissão de enfermagem ganha um status de profissão paramédica acentuando a dependência em relação à medicina.

A contribuição da sociologia para o campo da saúde tem se configurado através dos estudos das desigualdades sociais centradas nas relações sociais de produção e reprodução. Mais recentemente, pesquisadoras feministas da área das ciências sociais, vêm incorporando por força da prática social feminista, as relações de gênero e /ou relações sociais de sexo como categorias de análise. Esses conceitos expressam e visibilizam as clivagens de poder entre os sexos e foram construídos no âmbito das práticas sociais do movimento de mulheres. Enquanto conceito que opera no campo relacional, gênero não designa mulher ou mulheres, mas as relações de poder e os processos interativos que ocorrem entre homens e mulheres.

Desta maneira, o primeiro conflito está posto. A dicotomia entre saberes de homens e saberes de mulheres, constitui-se em força antagônica propulsora de relações de poder e de hierarquias.

Freqüentemente evidenciado "o mal-estar da enfermagem", reside ainda tanto no hiato existente entre uma realidade de trabalho funcionando principalmente sob o modo de emprego assalariado, subordinado a lógica e as exigências burocráticas, aos procedimentos medicais do sistema hospitalar, como pela concepção da prática de cuidar, calcada sobre o modelo da profissional liberal, com os ideais e autonomia que estes implicam. Ou seja, evidencia-se um segundo problema o de identidade.

O jogo entre tais conflitos parece estar centrado num conjunto de representações do feminino e do masculino que vêm sendo construído ao longo da história social da profissão de enfermagem, e que tem se evidenciado na configuração da identidade profissional, produtora de uma cultura da profissão e da constituição de um "campo científico" próprio. Identidade aqui é tomada como “... témoigne de l'existence d'une sujet individuel qui se fai reconnaître par sa famille ou sa communauté tout comme d'un sujet collectif qui veut se faire admettre dans le concert des peuples. Dans un cas comme dans l'autre, il s'agit d'echapper à l'éparpillement et à l'insignificance." (Ostrowetsky, 1995, p.1). Na realidade são duas dimensões da mesma categoria, isto é a do particularismo de um lado, e do geral de outro, ou do indivíduo de um lado e do universalismo de outro que agem de acordo na constituição do eu individual ou coletivo. Em síntese, a reivindicação da identidade nada mais é do que a luta de um indivíduo ou de um grupo contra a dominação de outro indivíduo ou de outro grupo.

A pluralidade de significados, a polissemia de sentidos da categoria identidade é tamanha que o fio condutor aqui privilegiado é a noção de gênero como parte constitutiva da construção identitária.

Retomando, as representações que envolvem a prática da enfermagem não 
são isentas de contradições e conflitos, porém, mesmo assim, asseguram a visibilidade à elementos do arquétipo de origem, ou na expressão de Miranda (1994) "do mito de origem". Neste sentido, o "mito fundador", de tradição secular que ronda o desassossego da enfermagem é por um lado, a associação à feminilidade, à mulher, à maternagem, a gestão da intimidade e ao cuidado dos corpos; por outro o caráter androcêntrico das relações de poder e a configuração da sexualidade que subjazem no espaço profissional da enfermagem.

Apesar de se caracterizar por uma estrutura profissional heterogênea e hierarquizada tanto em relação aos atores sociais como em relação as funções e atribuições, a enfermagem revela-se como evidencia que permite, de forma exemplar, conjugar a relação entre relações de gênero e relações de poder que vão pulverizar (para não dizer comprometer) tanto uma cultura da profissão, como o espaço e as relações de trabalho.

Assim, neste texto, pretende-se introduzir alguns elementos teóricos que possam ajudar a pensar articuladamente as relações profissionais da enfermagem, a partir de como estão comprometidas por conteúdos de ordem moral, historicamente produzidos, como produto da própria “... história do mito de origem da enfermagem moderna” (Miranda, 1994, p.11). Énesta história onde se ancoram e se sustentam as ambigüidades, os mal-estares que interferem na construção da identidade profissional e na atuação da categoria.

\section{REPRESENTAÇÕES SOCIAISDA ENFERMAGEM EM RELAÇÃO A CONDIÇÃO DE GÊNERO.}

A enfermagem no Brasil, é uma profissão construída socialmente como feminina, de mulher, a imagem e semelhança da professora primária, da assistente social e da serviçal doméstica, historicamente, da ama de leite. O caráter feminino alude a definição de trabalho como tarefa, que compõe o conjunto do desempenho profissional de serviços caracterizados como: higienizar, cuidar, curar, ajudar, confortar, alimentar, suportar, entre outros. Resumidamente, a profissão é composta majoritáriamente por mulheres e representada no imaginário social como atividade pertinente e apropriada à natureza feminina; associam-se e naturalizam-se as características da profissão como sendo tarefas naturais das mulheres exemplificando; os atos de cuidar da vida, dos doentes, dos velhos, das crianças; ou seja, engloba todas as dimensões afetivas que envolvem o ato de cuidar "soins", bem como a privacidade e a intimidade que são construídas nestas relações, presentes no imaginário social e popular, tem um valor fundamental, oscilando ora como atributo do sagrado, ora do profano. Vale destacar o que afirma Fonseca(1996, p.65) que ".... trabalho dos cuidados é conjugado no feminino e mostra-se como prática social sexuada. convoca para o seu exercício, contingentes de mulheres que, de acordo com o "dever - ser da enfermeira", necessitam de atribuições que não se enquadram na ordem de conhecimentos técnicos - científicos: precisam ser dotadas de qualidades [ habilidades] .... naturais e intrínsecas a natureza feminina e reveladoras de sua condição de reprodutora .... [qualidades tais como] .... paciência, perspicácia, auto-controle, auto-sacrifício, abnegação, devotamento, desinteresse, 
lealdade, obediência, disciplina, organização, discrição, sobriedade, pontualidade, coragem, docilidade, senso prático, confiança em si, integridade, pureza, honestidade ..."tais "habilidades" são tidas como inerentes à biologia e peculiares ao espírito das mulheres.

Tais qualidades femininas se auto-organizam-se com as propriedades do "cientificamente correto", como a inteligência, abstração, criatividade, racionalidade, naturalizadas como masculinas, cuja dinâmica e articulação responderia ao politicamente correto. Porém, cabe perguntar se a ciência tem um sexo? Ou seria mais pertinente perguntar se existe alguma incompatibilidade entre mulher e razão? Seriam os critérios de gênero que determinariam a ciência ? Apenas para ilustrar relato a seguinte passagem: "Paris, março de 1772, o inocente senhor Thomas, ilustre acadêmico, publica um Ensaio sobre as mulheres. Ele certamente não imaginara em que problemas tal Ensaio Ihe colocaria: Ao indagar no Ensaio a questão essencial: o que é uma mulher ? Obteve duas respostas: a de Diderot e a de Madame d'Epinay (que com duzentos anos de antecedência anunciaram o grande debate feminista do séc. XX). "A mulher é um ser de cultura inteiramente moldado por sua educação, dirá Madame d'Epinay. De modo algum responderá o filósofo Diderot: o destino feminino inscreve-se em letras naturais. A mulher é sempre governada, em última instância, por seus órgãos, e mais recentemente por seu útero". (Relatado por Badinter, 1991, p.9) .... Como se observa as coisas só mudaram de lugar e de tempo, porque na essência continuam [ praticamente] as mesmas." (Fonseca, 1996, p.65).

Outra associação com a natureza biológica feminina remete a figura da mãe; ou seja, qualidades de mãe como, ser honesta, pura, disponível, carinhosa, dedicada, desprendida, zelosa. Esses atributos são considerados como dignificantes da imagem feminina, na construção de um ser voltado para o outro, para servir, para doar-se e para cuidar. Neste sentido, ficam evidentes duas características: primeira, há na assertiva a negação de uma subjetividade feminina, da condição de um sujeito autônomo e próprio, cuja existência é filtrada pela naturalização destinando-a à subserviência; segundo, há uma moralidade interiorizada que reproduz-se como vocação e como ação moral. Este traço subjacente se consolida numa perspectiva sócio - moral de sujeito, e é o que o situa em relação aos demais.

\section{RELAÇÕESDEPODERE RELAÇÕES DESABER NO CAMPO DAENFERMAGEM.}

As estruturas fundantes tanto no plano real quanto simbólico, da sociedade capitalista assentam-se ainda na dinâmica do patriarcado (androcêntrico) assegurada pelo primado da virilidade, da masculinidade, e da divisão hierarquizante do mundo em masculino e feminino, fazendo-os funcionar de acordo com os atributos já internalizados. Como afirma Fonseca (1996, p.68) “.... pormeio do habitus sexuado, como cumplicidade ontológica, e que funciona tal como uma espécie de superego, as formas de classificação social deixam de ser transcendentais para se tornarem sociais, arbitrárias, socialmente determinadas e relativas a um grupo particular". As formas de classificação dos sujeitos sociais, em mulher (natureza), homem (cultura), atendem a princípios arbitrários que em relação aos sexos não apenas 
diferencia, mas subordina, hierarquiza e desiguala as mulheres em relação aos homens. Ora, tal sentimento é mascarador da legitimidade da existência não da enfermeira - mulher, mas também de sua identidade profissional e portanto da consciência de sua importância como valor social.

Nas profissionais da enfermagem, a obstinação desta não legitimidade da identidade profissional tanto pelo lado dos médicos como em boa medida pela própria categoria, ao não reivindicarem sua identidade, criam as condições que as levam a adotar por extensão a identidade daqueles que as dominam. Isso fica claro nos relatos das enfermeiras conhecidos como processos de "somatização da dominação", (Fonseca, 1996), no qual as enfermeiras ao mesmo tempo dominadas pelos médicos e se identificando com eles repassam essa dominação acumulada agindo de forma dominadora em relação às demais agentes da enfermagem técnicas, auxiliares, atendentes etc., e assim sucessivamente. Portanto, nestes termos, é importante visibilizar que a estrutura patriarcal a sociedade auxilia a tessitura de campos ocupacionais, alocando e classificando os sujeitos em postos mais ou menos valorizados, mais ou menos qualificados, de acordo com o seu sexo, pois é o próprio trabalho que passa a ser avaliado de acordo com os atributos sociais atribuídos pelo homem .

O que está submerso nestas classificações e hierarquizações são relações de dominação e de poder, inculcadas no individual e no coletivo e que operam na produção do masculino e do feminino. A elas são associadas valores que perpetuam um status quo de dominação vinculado ao do saber.

Nos termos deste trabalho, pode-se pensar a relação de dominação subordinação homem / mulher extensivamente a dimensão profissional concreta médico / enfermeira nas práticas do tratar / práticas do cuidar. Ainda a relação de dominação é múltipla e desdobrável, ocorrendo concomitantemente nas oposições em relação aos gêneros - homem e mulher; em relação aos profissionais - médico e enfermeira; em relação as qualificações profissionais - saber médico e saber da enfermagem; em relação ao conteúdo axiológico das práticas profissionais, tratar e cuidar. À esta capilarização da dominação pode acrescer-se tantas outras como a dominação pela diferença de classe, de raça, de idade, de região, de geração entre outras.?

A dominação enquanto relação se fundamenta numa moralidade que tanto instrumentaliza a aquisição de qualificação e experiência, como influi na qualificação requerida, dos profissionais da saúde - médicos e enfermeiras, - no sentido de adequarem-se diretamente às classificações de prestígio, as definições de postos de poder. Ora essas construções são todas ideológicas, produtoras de sentidos, de significados que vão se traduzir nas exigências de qualidades para as mulheres e de qualificações para os homens, justificando assim a demarcação de hierarquias de gênero no campo da saúde.

Portanto, há uma valoração distinta do masculino e do feminino, simbólica e real construída tanto pelas relações de poder quanto pelas relações de saber, que reproduzem-se numa hierarquia de gêneros (Oliveira, 1996).

A hierarquia de gênero pode claramente ser exemplificada pelos lugares 
socialmente definidos (pelo gênero) da medicina e da enfermagem: homem - médico e mulher - enfermeira. Quando se dá uma inversão destes (homem - enfermeiro e mulher - médica) o prestígio de gênero permanece. A médica é mais valorizada do que o enfermeiro, não por ser mulher, mas por exercer uma profissão que historicamente foi construída hierarquicamente superior pelo e como masculina. Neste sentido, a dominação ganha visibilidade na constituição da cientificidade dos campos - médicos (homens) mais científicos, mais cientistas, mais qualificação; enfermeiras, mais técnicas, mais atributos, mais qualidades. Isso decompôe-se na divisão social e sexual do trabalho como elemento gerador de conflito entre obediência e desigualdade.

Nessa perspectiva é possível compreender como se instala também a relação de ambivalência que se mantém na definição identitária da profissão. Ou seja, a enfermagem ora definida e classificada como trabalho - profissão, como atividade coorderiada de caráter racional e físico necessária a realização de trabalho com competências próprias, específicas, ou seja, um empreendimento especializado; ora é vista como tarefa, emprego que remete a uma ocupação cujas características são de desempenho mais manual, de serviço particular, de utilidade mais restrita, ocupação mais mecânica. Segundo o Aurélio, a idéia de tarefa remete simbolicamente a idéia de castigo, ou seja, a idéia de suportar, de obrigação associada ao castigo e ao trabalho rude. ${ }^{8}$ Esta ambivalência entre as noções de trabalho e de tarefa desqualifica os atributos científicos e técnicos da profissão de enfermagem sempre tendo como parâmetros os atributos da profissão médica, além do que é confusa a elaboração "..... de uma aspiração a um reconhecimento social de cientificidade, exigido para se obter espaço político e de poder dentro da razão moderna, do saber e do poder por ela produzidos." (Miranda, 1994, p.27)

Em decorrência, instala-se uma resistência no sentido de compreender a abrangência e as mediações entre as categorias trabalho e tarefa, trabalho e emprego ${ }^{9}$ como um campo mais alargado de competências que envolvem racionalidade e afetividade. Esta dinâmica híbrida entre razão (profissional) e afeto - sentimento (pessoal) devem possibilitar uma reconceitualização ampliada das categorias trabalho e emprego (que será discutida mais adiante a partir de Hirata (1994), e Nunes (1996) enquanto dinâmicas mais abrangentes e complexas e não pela redução (tentação) hierarquizadora destas categorias na construção da identidade profissional de médicos e enfermeiras.

Em síntese, cabe-se perguntar como estas representações (apesar de existirem uma variedade de outras) permanecem instruindo subjetivamente e com eficácia a produtividade e a prática profissional da enfermagem institucionalizada? Ou seja, o que interessa compreender é o fio condutor de sua lógica de sustentação, de permanência e de atuação na elaboração tanto da identidade profissional como na cultura da profissão de enfermagem, objeto do próximo item.

Para concluir ".... o importante a reconhecer é que as mulheres podem fazer o que os homens fazem. O que determina isso não é o conteúdo do trabalho feminino tomado a partir de suas exigências técnicas e do grau de conhecimento, e sim, a sua posição na escala de (des) valorização ocupacional tanto do mercado como da cultura, uma vez que esta é em grande medida reflexo daquele." (Bandeira, 1996, p.5) 


\section{NOÇÃO DE MORALIDADE E COMPETÊNCIA NA CONSTRUÇÃO DAS REPRESENTAÇÕES PROFISSIONAIS}

A emergência da enfermagem moderna como prática profissional assentase, historicamente como afirma Miranda (1994, p.33), nas conseqüências do que no “.... século XVII e XVIII marcaram na Inglaterra, um ponto crucial e decisivo na história .... o grande movimento da moralidade, comumente chamado de puritano, começou a transformar a "velha" e alegre Inglaterra num mundo mais sóbrio e firme. A minuciosidade da demanda puritana por uma consciência emocional e moral em várias áreas da vida .... é notável, como é o grau em que esta demanda se estendeu em direção a todas as classes da sociedade” (grifos nossos). A nosso ver, o malestar da profissão de enfermagem está ancorado nesta história, fundadora de um "mito de origem" (Miranda, 1994, p.15), que até hoje exerce algum tipo de influência sobre a profissão. O conceito de moral aqui tomado define-se como e refere-se a conduta dirigida ou disciplinada por normas ou pelo conjunto delas, auto-imposta ou imposta por outros, consideradas como válidas, quanto de modo absoluto para qualquer tempo ou lugar, quer para um grupo ou pessoa determinada. Ainda há dois significados correspondentes ao substantivo moral; primeiro, atinente a doutrina da ética; segundo, atinente à conduta e portanto susceptível de avaliação moral. Assim, não apenas pode-se falar de atitude moral ou de uma pessoa moralmente avaliável, mas pode-se entender também pelas mesmas expressões: profissões, ocupações, tarefas, coisas positivamente ou não avaliáveis. (ver a este respeito Abbagnano, 1982).

Hegel(1980) distingue a moral da ética porque a primeira, expressa a "vontade subjetiva", isto é, individual, desprovida do bem enquanto eticidade. Mas a moral e a ética compartilham do entendimento de serem tomadas "como condutas dirigidas e disciplinadas na realização do bem individual e em instituições históricas. ”(Abbagnano, 1982, p.1393)

Portanto, a moralidade consiste em assumir como móvel de ação a idéia de norma, de conduta e de dever. Nesta perspectiva, a enfermagem moderna, que teve sua origem no século XIX, na Inglaterra vitoriana, tanto pelos seus ideais como pela obra de Florance Nightingale, remete-se às representações seculares do chamado puritanismo, onde se elaborou tipos ideais de moralidade, bem como estágios hierárquicos de sua concretização. Miranda (1994, p.20) relata que “... até meados do século XV a enfermagem era função quase que exclusiva da Igreja, sendo chamada "o espírito cristão" o seu eixo orientador. Desde a época vitoriana, as práticas de saúde eram predominantemente realizadas pelas mulheres religiosas e leigas. A rigidez disciplinar, o auto-controle, a assexualidade (a metaforização do "anjo branco"), a firmeza entre outras, eram características morais que demarcaram o comportamento das iimãs de caridade elou religiosas. As leigas, deixadas a lascividade, eram mulheres bêbadas, miseráveis, rudes, prostitutas, desonestas, sem formação, portanto nelas ausente qualquer componente da moralidade. Instalase como representação, a metáfora a santa (mulher, mãe, religiosa, solteira, etc.) de boa origem sócio-econômica e na negativa a puta (lasciva, pobre, imoral)" 10 . Assim, o arquétipo de origem se funda sobre um sujeito não pleno e histórico, mas dividido, dicotomizado pela moralidade predominante e responsável pelos princípios identitários norteadores da profissão de enfermagem. 
A Reforma, expulsando as religiosas dos hospitais, precipitou o "período negro da enfermagem", fazendo aparecer a "enfermeira" do tipo descrito por Charles Dickens, no seu romance Martin Chuzzlewitt. Vale destacar como afirma Miranda (1994, p.26) ".... que até meados do século XVIII a medicina e o hospital permanecem independentes ... o hospital até então era uma instituição de assistência e de exclusão. De assistência ao pobre que não é preciso curar, mas é preciso assistir, pois ele está morrendo, e de separação/exclusão, na medida em que o pobre doente precisa ser recolhido para evitar o contágio dos outros". Os personagens, sobretudo as mulheres que se ocupavam do hospital ".... estavam mais propensas a alcançar a sua própria salvação espiritual do que a buscar a cura do doente. Eram pessoas religiosas ou laicas que estavam no hospital para fazer uma obra de caridade que Ihes garantisse a salvação eterna da vida espiritual"(idem, 26). Desde aquela época os conflitos já afloravam: de um lado o ethos religioso e a moral, que eram princípios do desenvolvimento do espírito cristão, idéia de dever, obediência; de outro, a expulsão que significando rejeição e desqualificação, ou seja, não mais a garantia do ato de pertencimento de reivindicação identitária. É a representação simbólica do não reconhecimento profissional.

Ainda segundo Miranda (1994, p.14) “..... o termo infirmiére data de 1398 e significa - "pessoa que cuida dos doentes numa enfermaria clínica de hospital"; ..... no ano de 1526 aparece o termo nurse ${ }^{11}$, na língua inglesa significando "mulher que amamenta ou que cuida"; em 1606 na França, aparece novamente o termo infirmiére e significa "local onde vivem as comunidades destinadas a receber e cuidar dos doentes, feridos, ou a Ihes dar os primeiros cuidados ....."; na língua portuguesa o termo aparece no século XIII como enfermar, igual a "ficar doente", (do latim infirmare).

Ora estes termos apontam para o significado de tomar conta de, $\ldots$ de cuidar de, .... de se ocupar de ....., todos tendo por trás uma figura de mulher e por extensão ".... a categoria "enfermeira", nurse ou infirmiére compreendendo significados que vão desde cuidar de doentes em ambientes hospitalares, à mulher que amamenta ou que cuida de outrem, suprimindo uma ausência ou carência (mãe adotiva, mãede-leite, por exemplo), quando em função adjetiva, a forma carinhosa de cuidar dos doentes, restrita às profissionais do sexo feminino" (Miranda, 1994, p.14).

Tais representações da profissão de enfermagem apesar de buriladas pelo tempo, ainda são nutridas por certos tipos de moralidade. Foi fácil observar nas trajetórias profissionais já realizadas alguns indicativos desta. Exemplificando, está internalizado na subjetividade de muitas depoentes, auto-imagens e concepções similares e o que é mais surpreendente é que são jovens, na maioria. Há certos traços comportamentais tais como, a importância da regra, de seguir as normas, de cumprir as ordens (mais do que dá-las, de recebê-las), do peso das práticas punitivas e sanções, todas estas regradas pelo reconhecimento do princípio do dever, da autoridade, da hierarquia. Tais indicadores de moralidade ainda muito visíveis e presentes vão exatamente ao desencontro da moralidade autônoma guiada pelas relações de cooperação, consciência, reciprocidade, e respeito mútuo; estas tanto podem emergir entre pares como entre não pares (enfermeiras entre si e/ou entre enfermeiras e médicos).

Ora, uma das questões ou dilemas fundamentais levantado por Nightingale, 
ainda no século passado, cuja polêmica remanesce, diz Miranda (1994, p.15) “...as enfermeiras deveriam ser chefiadas por uma supervisora enfermeira e não por um médico ou um sacerdote, como era hábito nos hospitais de então ..." (grifos da autora). Ou seja o dilema da regra, da autoridade, da obediência, em contraposição a autonomia, independência e reciprocidade se colocavam desde sempre. Aqui não apenas na composição fundante da própria identidade, mas como elemento identificatório, que permanece nas relações de poderes e de saberes entre médicos e enfermeiras.

Usando Piaget citado por Venturini Jr. (1995, p.11) que afirma “.... como a autonomia moral pressupõe que a consciência considere a regra como um ideal necessário, independente de qualquer expressão exterior, a noção de reciprocidade, que só pode surgir em relações de cooperação, será o principal fator de propulsão em direção à autonomia. Conclui Piaget; a autonomia só aprece com a reciprocidade, quando o respeito mútuo é bastante forte, para que o individuo experimente interiormente a necessidade de tratar os outros como gostaria de ser tratado." (grifos do autor). Portanto, a regra, a obediência e a autoridade, não são nefastas nem perversas em si mesmas, mas a sua internalização e uso advindo de transmutação de uma relação de dominação / subordinação é que vai instalar as fraturas na identidade profissional da enfermeira, estabelecendo como valores: religião, (in) consciência e punição.

A enfermagem moderna assentada na proposta de Nightingale não se livrou destes arquétipos, embora buscasse incorporar-se ao projeto da ciência e da razão modernas. Assim, apropriou-se de um dos elementos de eficácia e de controle da modernidade - a disciplina. Como resultante do tripé vigilância constante - espaço individual - individualizador e classificativo registro contínuo (Miranda, 1994). O poder disciplinador vai se constituir num dos elementos da moralidade fundante da futura identidade profissional. A disciplinarização das mentes e dos corpos que assentam-se nos elementos da moralidade são determinantes: obedecer implica obedecer alguém, uma autoridade (exterior, externa), vigilância, auto-controle e controle de seus pares; ordens normativas para o comportamento moral elevado. Além desses atributos, outra premissa de Nightingale era quanto a origem social. As primeiras enfermeiras foram as ladies-nurses e as nurses. As ladies-nurses tinham origem aristocrática e burguesa, as nurses oriundas dos segmentos proletários e populares. Essa divisão social era obviamente extensiva a todas às atividade da enfermagem: entre si criaram-se "micros poderes" estabelecidos nas relações de dominação e controle; em relação as nurses estas eram castigadas com a atribuição das tarefas mais duras e grosseiras. como afirma Miranda (1994, p.29) “... um poder que não é apenas repressivo, que proíbe e castiga, mas que diz sim, que concede, que possui uma positividade e, como conseqüência, uma produtividade"12. Portanto, se legitima. 


\section{SEXUALIDADE E MORALIDADE: OS COMPONENTES DA IDENTIDADE PROFISSIONAL DA ENFERMEIRA}

O "modelo Nightingale" plantou raízes e deixou frutos na configuração da enfermagem moderna. Florence Nightingale (1820 -1910) era de origem burguesa, filha de ingleses, ficou solteira a vida toda, era extremamente culta, mulher de princípios rígidos foi a fundadora do Corpo de Enfermeiras Laicas, viveu 90 anos todos dedicados a causa da enfermagem. Foi profundamente influenciada pelo puritanismo inglês que se visibilizou pelo "rígido padrão moral e espiritual, que se baseava na constância de caráter e na introspecção" (Miranda, 1994, p.154). Isso produziu um temperamento auto-controlado, firme, severo, com sentimentos e emoções contidas, com grande senso de responsabilidade social e humanitária.

Este "..... ideal de constância, extensivo à aflição, ao amore ao prazer erótico rejeitava a vida monástica [espartana] e o celibato. Ao contrário, havia um apelo ao casamento, desde que baseado nestes componentes" (Miranda, 1994, p.35). A da sexualidade, não era negada mas havia o seu controle. "o preço da constância, da fidelidade e da firmeza de sentimentos é o sacrifício da intensa excitação." (idem, 35) A té o século XVIII ainda predominava a idéia de que as mulheres eram as lascivas, mais perniciosas e perigosas do que os homens. Certamente esse imaginário tem suas raízes no processo de caça as bruxas que se iniciou do século $\mathrm{XI}^{13}$ mas que em meados do século XIII, começaram a se inverter os papéis e a posse da luxuria, da volúpia e do desejo carnal entre homens e mulheres passa a migrar ao domínio dos homens.

Assim, a noção de "mulher de verdade" introduzida pelo puritanismo inglês, apresentou o gênero feminino como uma nova pudicícia, afirma Miranda (1994, p.35) “.... ela não se interessa por sexo e é mais ética do que o homem: as mulheres se tornaram o sustentáculo da civilização e da cultura moral, eo homens, o sustentáculo da energia, da vitalidade e da sexualidade." Assim, o ideal feminino baseado na moralidade como fonte controladora e porque não dizer como condenadora da sexualidade. O sexo passou a ser proibido, associado ao sujo, ao feio, ao repugnante, relegado a um recôndito silêncio. Quanto mais escondido, maior o segredo e mais valorizado como tal.

Traduzidas em alguma medida pelo "Modelo Nightingale" tais princípios, centraram-se na preocupação com a conduta pessoal e moral das alunas de enfermagem (trajar, gestos, maneiras, comportamentos, etc.). O Boletim Moral reproduzindo a moralidade de Nightingale era usado nas escolas de enfermagem e traz alguns elementos curiosos relatados por Miranda (1994); primeiro, havia a preocupação com os cabelos - símbolo feminino da sexualidade; daí os cabelos curtos, presos ou o uso de gorros que escondessem os cabelos; o estado das unhas e dos lábios deveriam estar sem pintura ainda, a noviça ${ }^{14}$ era proibida de sair só do hospital; uma noviça dificilmente seria aceita antes dos 30 anos, idade que configurava uma não - opção pelo casamento e consequentemente pela sexualidade. Esta aqui compreendida, segundo Miranda(1994, p.36) “.... sexualidade como pulsão de vida, não designando apenas as atividades e o prazer que dependem do funcionamento do aparelho genital, mas toda uma série de excitações e de atividades presentes desde a infância, que 
proporcionam um prazer irredutível à satisfação de uma necessidade fisiológica fundamental (respiração, fome, função de excreção, etc.) e que se encontram, a título de componentes, na chamada forma normal do amor sexual".

A "Revolução Nightingale" em síntese não desprezava a sexualidade, porém, confirmava-se como produtora de um erotismo discursivo, no qual a sexualidade ficava restrita e enclausurada. A sexualidade ficou assim protegida na discrição de poucos locutores, senão no silêncio privado de outros poucos.

As conseqüências desse modelo até hoje estão presentes na prática da enfermagem: “.... a enfermeira é a profissional da área de saúde que tem maior autorização social para tocar o corpo do outro. Não o toque objetivo e rápido do diagnóstico médico .... refiro-me aqui ao exercício técnico de uma profissão que se faz basicamente pelo contato com a pele do outro. O "paciente" considerado assexuado .... recebe esse toque, que vai desde os cuidados da higiene - banhos, massagens, relaxamento, visando proporcionarbem-estar, à determinadas técnicas de preparo para exames .... Há, ainda hoje a interdição absoluta de se adicionar a discussão sobre a sexualidade às questões da prática da enfermeira, como a época de Miss Nightingale." (Miranda, 1994, p.37)

O que sustenta essa lógica é a nosso ver, mais a preocupação da quebra desse "encanto", desse "erotismo discursivo", do que a própria ruptura que poderia vir a ocorrer no domínio da própria sexualidade. Concluindo, “..... poderíamos pensarque a própria autorização social para tocar o corpo do outro atauria como um dos agentes formadores da noção dualista que remete à divisão entre o sagrado e o profano: irmã de caridade, devota, bondosa, caridosa, assexuada e virgem, por um lado, e por outro, exemplificada, ... como sedutora, subornável, promiscua, fácil, incompetente e desonesta" (Miranda, 1994, p.38)

A enfermagem como profissão no Brasil seguiu estas mesmas pegadas, desde a criação da Escola de Enfermeiras do Departamento Nacional de Saúde Pública, em 1922 futura Escola Anna Nery (1926) até nossos dias. Simbolicamente todos estes signos da moralidade fundante da profissão foram em alguma medida seguidos interiorizados. Talvez com maior rigidez no passado porque só aceitavam moças de boa origem sócio-econômica, apenas de cor branca e portadoras de diploma do Curso Normal. Imbuídas do ideal burguês buscavam a qualquer custo a higienização da trama social; prevenção, eugenia, beleza e limpeza. Hoje a situação seria outra?

\section{A TENTATIVA DE RECONCEITUALIZAÇÃO DA CATEGORIA TRABALHO: DA SUBJETIVIDADE ÀS PRÁTICAS SOCIAIS DA ENFERMAGEM}

A categoria trabalho não pode mais ser pensada pelo olhar dos conceitos clássicos de análise como o de classe por exemplo e visto pelo olhar da dominação e da hierarquização. A redefinição da categoria vem sendo pensada por vários autores, dentre os quais Hirata (1994), Dejours (1995), Cours-Salies (1995), Kergoat (1994) Nunes e Soria (1996) entre outros.

Para Hirata (1994) a reconceptualização da categoria vem ocorrendo a partir da introdução da noção de gênero, que altera a dimensão de masculino presente no conceito, uma vez que historicamente o conceito de trabalho foi estabelecido pelo 
olhar androcêntrico, produzindo a divisão sexual e internacional do trabalho. A análise sobre as relações sociais de sexo, nessa perspectiva repousa em relações inigualitárias, hierarquizadas, assimétricas, antagônicas, de exploração e opressão entre duas categorias construídas de atores sociais - masculinos e femininos. Diz Hirata (1994, p.81) "..... la réflexion sur la crise du travail se situe dans le cadre d'un essai de reconceptualisation de la notion même de travail a partir de l'introduction, dans le centre de l'analyse, de la dimension "genre", ou "sexe social" et de la dimension "nord-sud" ou "division internacionale du travail ....".

Para, além da noção de classe, a noção de gênero foi incorporada considerando que nenhuma é mais ou menos necessária do que a outra. Foi Kergoat (1994) que deu estato conceitual a estas duas categorias em termos de "coextensividadé". Isto é, em termos de abrangência parcial de uma em relação a outra. Para Hirata (1994, p.82) “.... il y a lá, un refus de hiérarchiser ces rapports sociaux ... un rapport social ne peut pas être un peu plus vivant qu'un autre; il est ou il n'est pas."

Ainda partindo da idéia de "co-extensividade", há uma indissociabilidade da exploração e da opressão nas categorias de trabalho assalariado e de sexo, ou seja "..... étant simultanément celle oú s'exerce le pouvoir mâle sur les femmes" (Hirata, 1994, p.82). Assim, a possibilidade de se pensar através da "co- extensividade" podese chegar ao conceito de sujeito sexuado inserido numa rede de relações intersubjetivas. (Kergoat,1994).

É para Hirata(1994, p.82) “.... esta passagem do primado, do econômico e das relações de exploração à afirmação de um laço (ligação) indissociável entre opressão sexual (e de classe) e exploração econômica (e de sexo), que permite, no meu ponto de vista, a re-conceitualizar o trabalho, de o dinamizar, a partir da introdução de uma subjetividade diligente (enérgica), ao mesmo tempo "sexuada" e de "classe", segundo a expressão de Kergoat" (grifos nossos).

Assim, a quebra da hegemonia masculina e a incorporação da subjetividade ao nível da reconceitualização permite uma ruptura também com as relações sociais codificadas, com procedimentos repetitivos e rotineiros vivenciados por homens e mulheres no espaço do trabalho. A idéia instrumental da dominação da hierarquização entre homens e mulheres, no trabalho, se apresenta sob a forma de uma classificação de "métiers", de profissões - trabalhos mais inteligentes, trabalhos mais manuais, mais repetitivos, mais executivos. Tais classificações não são derivadas exclusivamente de uma realidade histórica particular, mas também decorrentes da diversidade dos seres masculinos - femininos, isto é de uma concepção naturalista da divisão do trabalho social.

Ao romper com a relação de dominação, visibiliza-se a idéia de sujeito, de indivíduo. Hirata (1994, p.83) afirma: “.... Cette pleine reconnaissence de la place de l'individu(e) et de la subjectivité dans le travail est une pré-condition permettant de saisir les mouvements et les rapports de passion dans les rapports de travail; et travailler surles modes de passage de faire l'étre: de distínguir, enfin, les modalités sexuées du rapport à l'espace, au temps et à société". (grifos do autor)

Do ponto de vista metodológico as conseqüências são muito positivas segundo a autora. Primeiro, porque os homens estão percebendo a importância de incorporar 
em suas análises sobre a divisão social do trabalho, as relações de gênero (relações sociais de sexo), com isso reconhecendo sua pertinência; segundo, porque concerne à categoria trabalho, maior abrangência no sentido de incorporar algumas ferramentas conceituais como por exemplo a criatividade. (Hirata, 1994) A autora exemplifica dizendo " La source essentielle de cette (nouvelle) produtivité réside, en derniére analyse, dans l'organisation de la criativité." (p. 84)

Pensadas tais questões para o campo da saúde podem indicar também uma redefinição na categoria trabalho, extensivas a divisão sexual do trabalho. Exemplificando, incorporar a dimensão da afetividade, do sentimento, da linguagem, das emoções no conceito de trabalho, tanto como elementos construtivos quanto como instrumentos de trabalho, além de incorporar dimensões, como a virilidade, a feminilidade, a bissexualidade psíquica são novas possibilidades que se abrem na busca de outras interpretações expressas, interpretadas, negadas ou inexploradas no trabalho.

Pensar a categoria trabalho para o campo da saúde a partir desta ampliação, traria certamente mudanças, além de mais clareza e benefício a todos os envolvidos - médicos, enfermeiras e doentes.

Exemplificando, ao redor do doente ${ }^{15}$ são desenvolvidos procedimentos técnicos, científicos e afetivos. As enfermeiras tem acesso aos signos corporais mais privados e íntimos do doente. São elas que no geral interpretam as manifestações do corpo e dos sentimentos: a ansiedade, angústia, o medo, o sofrimento, a esperança. Esses signos não são apreendidos necessariamente pelo desempenho técnico, mas é o afetivo, é o sentimento, é a linguagem simbólica quem os percebem. Como tornar tais signos inteligíveis ? Seja para proceder a um diagnóstico, seja para aprender as percepções subjetivas da doença.?

Neste âmbito o conceito de trabalho seria permeado tanto por novos e singulares elementos como pelo deslocamento das fronteiras do masculino e do feminino, acarretando assim mudanças no processo de divisão social e sexual do trabalho.

No caso particular da saúde e da relação médico - enfermeira é que se visibilizam práticas discriminatórias. Às mulheres - enfermeiras, as qualidades são consideradas atributos naturalizantes e não são aceitos como qualificação. Aí se funda a discriminação e a relação de dominação dos médicos em relação as enfermeiras, o que alija toda possibilidade de produzir relações sexuais e de trabalho envolvendo a ciência e afetividade na prática profissional. Para concluir remeto novamente à Hirata $(1994,88)$ quando afirma: “.... on pourrait dire que tant la variabilité que la persistence de la division sexuelle du trabail peuvent être retrouvées dans le temps et dans l'espace, mais que la diachronie est la dimension privilegiée pour saisir la permanence, comme la synchronie l'est pour saisir la variabilité".

\section{IDENTIDADE DE GÊNERO E MORALIDADE DO CUIDAR}

É ingênuo pensar que o "mal-estar"da enfermagem em relação a formação de sua identidade profissional se circunscreve apenas a questão das relações de poder médico-enfermeira, que ao final se torna reducionista do problema como afirma Miranda (1994). 
Ao contrário o "mal-estar" passa também pela não percepção da própria categoria da importância real e simbólica que representa o ato de cuidar da vida (acte de soins). Este ato fundamenta-se na moralidade e na competência. O sentido da palavra moralidade é captado pelo enfoque de Gilligan (1982) dá sobre os elementos do cuidado e da responsabilidade, mais claramente evidentes nas relações de obrigações especiais com a família e com os amigos. "A primeira é que eles implicam alguma consideração com o bem-estar de outra pessoa; a segunda, é que eles envolvem um sentimento de responsabilidade ou obrigação; a terceira, é que eles envolvem uma tentativa de_comprometimento em uma comunicação ou diálogo com as partes envolvidas" (grifos do autor) in (Venturini Jr., 1995, p.66).

Assim, ao analisar o ato de cuidar da vida, centra-se no alvo da questão. Este envolve necessariamente mais do que os aspectos técnicos e científicos. Envolve a afetividade, a palavra, o ato de tocar, a percepção, isto é, todas estas dimensões que não são exclusivas da razão, mas que de alguma maneira, a ela se associam.

Daí porque a atividade de decomposição e recomposição científica não dá conta por si só de captar as singularidades, as subjetividades de uma pessoa, sobretudo de uma pessoa doente - enferma.

A noção de cuidar (care oposta a noção de cure), envolve a dimensão da afetividade, implicando certos valores, qualidades e sentimentos: a atenção ao outro; a sensação de inquietação pelo outro; o sentimento de estar concernido, interessado, empenhado; relacionar-se através do caminho, da ternura, da maternagem ${ }^{16}$. Estas são todas qualidades transformadas em qualificações que não implicam, ao serem praticadas, na ausência de procedimentos médicos, científicos e técnicos.

A noção de cuidar definida como um trabalho se torna singular na medida em que estabelecem vínculos relacionais entre a afetividade e ciência. É equivocado pensar que esta dimensão afetiva-humanitária no ato de cuidar pode ser reduzida ao olhar religioso, a uma visão da moralidade cristã. É mais do que isso, é a possibilidade da prática da enfermagem incorporar e valorizar como instrumentos de trabalho estas dimensões que exigem competência e atenção próprias e .pessoais - isto é, são qualificações. Esta noção de care é incompatível com a estandartização das instituições hospitalares, onde a noção de tempo, de normas, de horários, de disciplinas, das cadências, de dependência hierárquica, todos estes componentes são suportes do contexto hegemônico técnico-científico altamente racionalizado e racionalizante.

É a partir daí que se estabelece e se sustenta a relação de poder e de saber do médico em relação a enfermeira e a cadeia de reprodução que esta representa. A universalidade científica da natureza humana é de natureza estatística; cada doente passa a ser visto como um caso estatístico em grau de complexidade variado. É destituído do enfermo a possibilidade de expressão de sua individualização que ocorre na relação mais solidária e porque não cristã; oposta ao tratamento estandatizado, assexuado e anônimo. São duas perspectivas que se contrapõem: de um lado, uma tem consciência médica, baseada nos parâmetros científicos da eficácia onde o doente é visto numa determinada circunstância, tendo tal tipo de doença, onde é indicada tal 
terapia, em tais condições, com x \% de sucesso, etc. Por outro, a dimensão interpessoal, que não dispensa uma lógica científica, mas que se baseia na relação solidária e afetiva, na palavra e no diálogo entre o profissional e o doente que se expressa através do ato de cuidar, que têm competências próprias e que cria um novo paradigma nas relações entre os personagens médico-enfermeira e doente.

Neste sentido há conjunto de competências próprias ou especificidades que podem (ou que são) desenvolvidas pela prática da enfermagem que lhe confere representações positivas, sem serem imorais.

- a capacidade de interpretar os signos corporais tanto na perspectiva da saúde quanto na doença;

- capacidade própria de aproximação dos corpos doentes (pacientes). Maior afetividade (laços mais afetivos, mais toques no corpo; o corpo do doente é mais tocado pelas mãos da enfermeira do que pelas do médico);

- apreender as percepções subjetivas do doente, da doença, ou seja, o perfil da história médica e individual do paciente, o consumo de sua terapêutica (farmacos), as próprias expectativas terapêuticas do doente;

- Conhecer a sintomatologia, isto é, a evolução dos sintomas da doença;

- Aprender a gestualidade (signos, imagens, mitos) dos doentes - exemplos: situações depressivas, angústia, etc. que caracterizam a "qualidade" do paciente.

- Registro de competências do profano (saberes conhecimentos, crenças sobre seu corpo, sua história, etc.);

- Estabelecer relações/vínculos com o universo familiar mais facilmente que o médico;

- Existência de formas arquetípicas de saúde-doença que revelam a existência de saberes práticos e conhecimentos que não podem ser inteiramente e diretamente dependentes das formas medicais usuais de saber e de conhecimentos médicos (é aí que entram as enfermeiras com todo o seu arsenal de informação, prática e cuidado). É onde se cria uma sorte de "dependência" entre o paciente e a enfermeira - enquanto que com o médico a relação é de autoridade em cima do discurso medical;

- Há uma forma própria de construção dos saberes e dos conhecimentos; o médico representa o doente, a enfermeira relaciona-se com o doente;

- O conhecimento de certos fatos patológicos pode ocorrer igualmente por um conhecimento simbólico ${ }^{17}$.

Para concluir, é importante que se pontue a ruptura teório-metodológica provocada pela introdução da subjetividade como categoria de análise: rompe com a hegemonia masculina e possibilita reconceitualizar as relações sociais codificadas e hierarquizadas, sobretudo no campoda saúde e nas relações de trabalho. Esta ruptura visibiliza o sujeito como indivíduo. Do ponto de vista metodológico as conseqüências são bastante positivas. Exemplificando para o campo da saúde ; incorporam-se a dimensão da afetividade, do sentimento, da linguagem no conceito de trabalho, da virilidade, da feminilidade e da sexualidade.

O uso destas categorias exige diferentes estratégias metodológicas e tem provocado mudanças significativas no marco teórico do cuidado com implicações 
concretas na prática profissional cotidiana das enfermeiras. Isto é, olhar o/a doente, o usuário/a não mais como pacientemente paciente, mas como um sujeito que traz uma história de vida, uma vivência marcada pela classe social, pela cor, pelas relações de gênero, que tem um corpo que designa um sexo, que tem uma sexualidade que passa pela opção sexual, enfim, que produz subjetividade e intersubjetividade nas diferentes relações sociais em que está envolvido.

São as enfermeiras que estão permanentemente ao lado deste(a) doente, portanto, são elas que têm acesso aos seus signos corporais mais privados e íntimos. São elas que interpretam os sinais do corpo, como a ansiedade, o medo, a angustia, a esperança, o sofrimento e a vergonha. Esses signos não são apreendidos pela competência técnica e sim pelo afetivo, pelo sentimento e pelas diferentes formas de expressão da linguagem.

A enfermagem é uma categoria que se construiu na heteronomia na relação com o outro. É neste sentido que a construção do campo de conhecimento da enfermagem, o cuidar e o cuidado, exigem um olhar interdisciplinar para desvelar a profissão não mais como um lugar de abnegação, mas como um lugar de profissionalização socialmente necessária e legitima.

O cuidado na perspectiva relacional opera dialéticamente no processo saúde-doença, e incorpora a subjetividade, a afetividade, a palavra, os gestos corporais, o ato de tocar, a percepção para além da técnica. Este é a nosso ver o grande desafio com o qual as/os profissionais de enfermagem têm que se defrontar, para a construção de sua identidade profissional do seu objeto de conhecimento, enquanto uma prática social de sexo e gênero. 


\section{NOTAS:}

${ }^{4}$ Este texto é parte de um diálogo travado entre a sautoras a partir de duas pesquisas mais amplas, uma sobre "As ambiguidades profissionais e condições de trabalho e de cidadania das enfermeir as - estudo de caso comparativo DF-SP" e a outra sobre "O impacto das condições de trabalho das enfermeiras do Hospital São Paulo em vida sexual e reprodutiva".

${ }^{5}$ É uma categoria basicamente formada por mulheres, assim distribuída; daquelas que têm o nível universitário 94\% são mulheres; das técnicas de enfermagem, 88,5\% são mulheres; $91,5 \%$ das auxiliares de enfermagem são mulheres; das atendentes de enfermagem, $88,5 \%$ são mulheres. (Fonseca (1996)

${ }^{6}$ A prática do curaré aqui compreendida como hegemônica da área médica e, que Ihe outorga um poder de vida e morte sobre o/a paciente, o/a usuário/.

7 Pesquisas já realizadas em hospitais indicam como tais relações de dominação e subordinação estão presentes nas funções atribuidas às mulheres. Exemplificando, Lopes, 1996:76/77 diz: "no hospital, os setores de higienização ambiental, os serviços de hotelaria, lavanderia, alimentação, dietoterapia,assistência social, terapia ocupacional ... entre outros são majoritariamente responsabilidade de mulheres. A cozinha por exemplo é exclusivamente espaço para as mulheres. Em síntese todos os postos administrativos de menor qualificação (secretárias, arquivistas, etc.) são tradicionalmente ocupações femininas." Os homens ao contrário, ocupam os postos clássicos (serviços de obras e manutenção, engenharia, carpintaria, segurança, compras, estoques de material; no setor administrativo, setor de informática e custos; os postos são de maior qualificação, de maiores salários e consequentemente de maior poder.

${ }^{8}$ No dicionário francês - Petit Robert (Paris, 1996 p. 1739) o verbete métier tem também a idéia de tarefa (tâche) é associada a tarefa pornecessidade (besogne), que significa algo imposto, necessário, remete a idéia de algo rude, pesado (Elle fait la grosse besogue ...); associar-se trabalho fatigante, repetitivo, desinteressante, abusivo, mediocre e mal remunerado.

${ }^{9}$ A esse respeito consultartexto de NUNES, Christiane G. F. e SORIA, Analia - "Crise Econômica e Crise na Cultura do Trabalho" que vão discutir a diferença entre as categorias - trabalho e emprego. (op. cit. na referênciabibliográfica).

${ }^{10}$ As imagens desta dualidade - santa - puta são brilhantemente registradas na literatura nos romanos de Charles Dickens, Oliver Twist e Martin Chuzzlewitt. Pode-se também destacar todo o registro imaginário que viveu a Europa nos séculos precedentes em relação as bruxas. (ver a respeito Bandeira e Siqueira, op. cit. 1994).

11 "A palavra é uma forma reduzida de Nourish (Nutrir) e, quando aplicada a uma mulher, significa "amamentar, cuidar ou simplesmente tornar conta de uma criança".... "segurar carinhosa e cuidadosamente nos braços". (Miranda, 1994:19)

12 Florence Nightingale instituiu um Boletim Moral e Técnico que como Folha Mensal do caráter pessoal e das realizações de cada enfermeira, como mecanismo de poder, controle e moralidade. (Miranda, 1994:30).

${ }_{13}^{13}$ Ver texto Da Resignificação das Bruxas, série Sociológica, No 102, Depto de Sociologia, UnB, 1994.

${ }^{14}$ Noviça é a mesma expresão que designando a moça que está interna no convento para se preparar ao futuro de irmã religiosa.

${ }^{15}$ A idéia de conceber a sexualidade como suja e nojenta, remete simbolicamente a suprimir as necessidades sexuais, ou estão ambivalentemente ligadas aos elementos de limpeza, higienização dos órgãos genitais. (A propósito consultar Focault - História da Sexualidade)

${ }^{16} \mathrm{Na}$ língua francesa o uso do termo é comum - maternage.

17 Por conhecimento simbólico entende-se a capacidade que se tem de associar sentido e símbolo de sorte que um conjunto de símbolos pode remeter à uma mensagem complexa, elaborada, refinada como pode ser um diagnóstico profano. 


\section{REFERÊNCIAS BIBLIOGRÁFICAS:}

B ANDEIRA. Lourdes. A incorporaç:ão do conceito de gênero no PAISM. Trabalho apresentado na I Reunião Nacional sobre Qualidade de Atenção nos Serviços de Saúde Reprodutiva. Aracaju, set. 1996. mimeo.

BANDEIRA, Lourdes; SIQUEIRA, Deis - Ressignificação das Bruxas. Série Sociológica, n. $102-$ Dept $^{\circ}$ de Sociologia, UnB, BsB, 1994.

BARTHE, Jean-François. Corps vu et maladie, l'approche empirique. In: Aspects du Corps Contemporain: Approche Sociologique. Cachiers du Centrede Recherches Sociologiques Cachier, n. 4, nov. 1985.

BOLTANSKI, Lac. La Souffirance à distance. Paris: Metailié, 1993.

DEJOURS, Christophe. Le travail, entre subjectivité et rapports sociaus. In: Cours - Salies, Pierre (org). La Liberté du Travail. Paris: Syllepse, 1995.

FONSECA. Tania M. G. De mulher a enfermeira: conjugando trabalho e gênero. In: Lopes, M. J. M. et al. (Orgss) Gênero e Salude. Porto Alegre: Artes Médicas, 1996.

FOUCAULT, Michel. História da Sexualidade I. A vontade de Saber. Rio de Janeiro: Graal, 1984.

FRESNEY, C. D.; PERRIN, G. Le Métier d'infirmiére en France. Paris: PUF, 1996.

GENDRON, Colette. Infirmiéres et infirmiers: parler pour vivre: In: GENDRON C. ; BEAUREGARO. M. (Orgs). L'avenir - Santé auféminin. Québec: Gaëtan Morin Éditeur, 1989.

HIRATA, Helena. Rapports Sociau de Sexeet Division du Travail. contribution à la discussion sur le concept de travail. In: BIDET, J.; TEXIER, J. (Orgs.). La Crise clu Travail, Paris: PUF, 1994.

KERGOAT, Daniéle et al. Les Infirmiéres et leur Coordination (1988-1989). Paris: Editions Lamarre, 1992.

KERGOAT. Daniéle. La Coordination Infirmiére. In MOUVEMENT SOCIALet DIVISION SEXUELLE DUTRAUAIL. Cahiers diı Gedisst n. 2, IRESCO CNRS, Paris, 1991.

LOPES, Marta Júlia M. O Sexo do Hospital. In: Lopes, M. J. M. et al. (Orgss). Gênero e Saúcle. Porto Alegre: Artes Médicas, 1996.

MÉDA, Dominique. Le Travail: une valeur em voie de disparition. Paris: Auber, 1995. 
MIRANDA, Cristina Loyola. O Parentesco Imaginário: história e representação social da loucura nas relações do espaço asilar. São Paulo: Cortez; Rio de Janeiro: Editora da UFRJ, 1994.

NUNES, Christiane Girar F.; SORIA, Amália. Crise Econômica e Crise na Cultura clo Trabalho. Brasília, Depto de Sociologia - UnB, 1996. mimeo.

OLIVEIRA, M. Eleonora. A Pscopatologia sexualizada do trabalho: a reconstrução de um conceito. São Paulo, 1996. Tese (Livre Docência). Departamento de Práticas em Saúde Pública, Faculdade de Saúde Pública da USP.

OSTROWETSKY, Sylvia. Les quatre vois de l'identité.In: MAROUF, N. (Org.). Iclentité Communcuuté. Paris: Les Cachiers du CEFRESS, LIHARMATTAN, 1995.

PETITAT, André. Science, affectivité et Singularité daus la relation de soins. Revue Internationale d'action communcutaire, n. 28/68, 1992.

ROSEMBERG, Fúlvia. Educação infantil, classe, raça e gênero. Fundação Carlos Chagas, SP, 1996. mimeo.

THOMAS, A. L., DIDEROT, Madame D’epinay. O que é uma mulher? Rio de Janeiro: Nova Fronteira, 1991.

VENTURINI Jr., Gustavo. Autonomia e heteronomia em moral sexual. Meio social, idade e gênero no desenvolvimento moral. São Paulo, 1995. Dissertação ( Mestrado em Sociologia). Universidade de São Paulo.

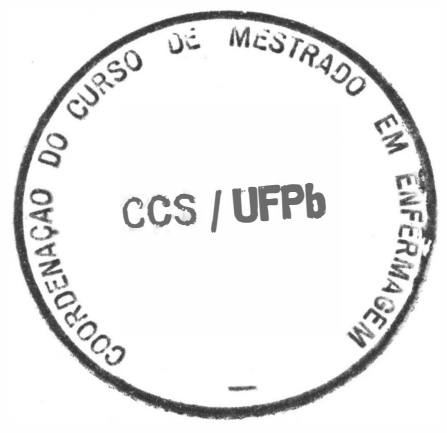

